\title{
MOVIMENTOS DAS NARRATIVAS NA EDUCAÇÃO MATEMÁTICA BRASILEIRA E O LUGAR DA HISTÓRIA ORAL
}

- HELOISA DA SILVA

Universidade Estadual Paulista “Júlio de Mesquita Filho"

MARINÉIA DOS SANTOS SILVA

Universidade Estadual Paulista "Júlio de Mesquita Filho"

RESUMO O artigo tem como objetivo a elaboração de uma compreensão inicial sobre a entrada e a movimentação das narrativas na Educação Matemática, bem como sobre o lugar da História Oral nesse movimento. Parte significativa deste estudo é resultado de uma pesquisa de doutorado em desenvolvimento, cujo objetivo é investigar o movimento de entrada, apropriação e circulação das narrativas na comunidade acadêmica da Educação Matemática, a partir dos grupos de pesquisa que estudam as narrativas na formação de professores que ensinam Matemática. Partindo do princípio de que as motivações das pesquisas com a História Oral na Educação Matemática diferem das demais pesquisas que abordam as narrativas nessa área, por seu envolvimento e compromisso com a historiografia, buscamos pontuar as singularidades e particularidades inerentes a essa metodologia - a História Oral. Salientamos também a complexidade e a pluralidade de temas que abordam as narrativas na Educação Matemática, bem como os espaços significativos, como os grupos de pesquisa, as associações, os congressos e os trabalhos científicos desenvolvidos pelos Programas de Pós-Graduação na área da Educação (Matemática) que corroboram a produção, a disseminação e o fortalecimento do movimento das narrativas na Educação Matemática.

Palavras-chave: Educação Matemática. História Oral. Narrativas. EDUCATION AND THE PLACE OF ORAL HISTORY

The article aims to elaborate an initial understanding of the entrance and movement of narratives in Mathematics Education, as well as the place of Oral History in this movement. A significant part of this study is the result of a doctoral research in development, aiming to 
investigate the movement of the entrance, appropriation and circulation of the narratives in the academic community of Mathematics Education. It is based on research groups that study the narratives in the formation of math teachers. Assuming that the motivations of Oral History research in Mathematics Education differ from other studies that approach the narratives in this area due to their involvement and commitment to historiography. We seek to highlight their singularities and peculiarities inherent to this methodology - Oral History. We also emphasize the complexity and plurality of themes that address the narratives in Mathematics Education, as well as the significant spheres such as research groups, associations, congresses and scientific works developed by the Graduate Programs in the area of (Mathematics) Education that corroborate to the production, dissemination and strengthening of the narrative movement in $\mathrm{Ma}$ thematics Education.

Keywords: Mathematics Education. Oral History. Narratives.

\section{RESUMEN MOVIMIENTO DE LAS NARRATIVAS EN LA EDUCACIÓN MATEMÁTICA BRASILEÑA Y EL LUGAR DE LA HISTORIA ORAL}

El artículo tiene como objetivo la elaboración de una comprensión inicial sobre la entrada y el movimiento de las narrativas en la Educación Matemática, así como sobre el lugar de la Historia Oral en ese movimiento. Una parte significativa de este estudio es el resultado de una investigación de doctorado en desarrollo, cuyo objetivo es investigar el movimiento de entrada, apropiación y circulación de las narrativas en la comunidad académica de la Educación Matemática, a partir de los grupos de investigación que estudian las narrativas en la formación de profesores que enseñan Matemáticas. A partir del principio de que las motivaciones de las investigaciones com la Historia Oral en la Educación Matemática difieren de las demás investigaciones que abordan las narrativas en esa área por su implicación y compromisso con la historiografia, buscamos puntuar sus singularidades y particularidades inherentes a esa metodología - la Historia Oral. Sin embargo, subrayamos la complejidad y la pluralidad de temas que abordan las narrativas en la Educación Matemática, así como los espacios significativos como los grupos de investigación, las asociaciones, los congresos y los trabajos científicos desarrollados por los Programas de Postgrado en el área de Educación (Matemática) que corroboran la producción, la diseminación y el fortalecimento del movimiento de las narrativas en la Educación Matemática.

Palabras clave: Educación Matemática. Historia Oral. Narrativas 


\section{Apontamentos iniciais}

Inumeráveis são as narrativas do mundo. Há, em primeiro lugar, uma variedade prodigiosa de gêneros, distribuídos entre substâncias diferentes, como se toda matéria fosse boa para que o homem the confiasse suas narrativas: a narrativa pode ser sustentada pela linguagem articulada, oral ou escrita, pela imagem, fixa ou móvel, pelo gesto ou pela mistura ordenada de todas estas substâncias; está presente no mito, na lenda, na fábula, no conto, na novela, na epopeia, na história, na tragédia, no drama, na comédia, na pintura [...] Além disto, sob estas formas quase infinitas, a narrativa está presente em todos os tempos, em todos os lugares, em todas as sociedades; a narrativa começa com a própria história da humanidade; não há em parte alguma, povo algum, sem narrativa [...] a narrativa ridiculariza a boa e a má literatura: internacional, transhistórica, transcultural; a narrativa está aí, como a vida. (BARTHES, 2011, p. 19)

Neste texto, buscamos apresentar uma compreensão do movimento de entrada e circulação das narrativas na Educação Matemática, no contexto brasileiro, bem como o lugar da História Oral nesse movimento. Uma parte significativa deste estudo vincula-se a uma pesquisa de doutorado, em desenvolvimento junto ao Grupo História Oral e Educação Matemática (Ghoem), cujo objetivo é compreender como se deu (e está se dando) o movimento de entrada, apropriação e circulação das narrativas na comunidade acadêmica da Educação Matemática, a partir dos grupos de pesquisa que estudam as narrativas na formação de professores que ensinam Matemática. Tal pesquisa, por sua vez, faz parte dos interesses do Ghoem, que há 20 anos investiga a história da educação matemática brasileira, sendo, parte relevante dessa investigação, a História Oral como metodologia de pesquisa.

1 Neste texto, utilizaremos a expressão “Educação Matemática", enquanto área de pesquisa, e "educação matemática", ao tratar de práticas e aspectos relacionados ao ensino e aprendizagem da matemática, de um modo geral.
Podemos afirmar que os movimentos de entrada e permanência das pesquisas em História Oral, na Educação Matemática, estiveram/estão fortemente preocupados com essa tessitura de compreensões sobre as culturas da educação matemática brasileira. Embora encontremos, já no início desse movimento, trabalhos interessados em questões da área sem um interesse explícito pelo viés histórico, ${ }^{2}$ por um longo tempo, as referências às entrevistas e ao seu tratamento visando a produção de fonte histórica, a valorização da fonte oral na compreensão de aspectos para a produção de conhecimento histórico e o engajamento em uma política do poder da fala, em detrimento do silenciamento de possiveis infames (ou sem fama), por meio da historiografia e da ciência, tiveram maior destaque em suas discussões.

No entanto, sempre esteve latente no grupo de pesquisa o interesse por analisar, compreender e teorizar, em trajetória, a História Oral como um método que valoriza, cria e mobiliza narrativas orais como fontes (historiográficas) para a pesquisa em (história da) educação matemática. A partir de um determinado momento, um conjunto de pesquisas em História Oral produzidas no Ghoem mostrou seu potencial na compreensão das culturas de matemática e educação matemática (sobretudo na cultura escolar) brasileiras, e indicaram assim, seu potencial em espaços voltados à formação de professores (de Matemática). Sobretudo por esse motivo, passou a haver no grupo o interesse pelo estudo das potencialidades da História Oral como abordagem pedagógica.

No que tange à pesquisa, a metodologia foi desde sempre concebida como em constante movimento, construção e análise pelos pesquisadores do grupo, justamente por entende-

2 Como, por exemplo, as teses de Vianna (2000), Rolkouski (2006) e Silva (2006). 
rem que o método é singular a uma pesquisa, intimamente relacionado ao pesquisador, pois são singulares seus questionamentos, compreensões, fundamentações e interesses de pesquisa. Em toda e qualquer pesquisa, não se usa um método, se cria um método.

No que se refere à abordagem pedagógica da História Oral no ensino e na formação de professores (de matemática), vale ainda ressaltar que o interesse por essa investigação está tanto vinculado à compreensão das potencialidades dessa metodologia, como também das narrativas (orais) que se produzem a partir dela, para atender aos objetivos de determinados espaços voltados à formação. Assim, em alguns momentos, embora tenha parecido redundante ou confusa a referência à História Oral e às narrativas nessas iniciativas, a ideia foi pontuar que, de fato, eram dois os movimentos de investigação realizados: um interessado nas potencialidades da metodologia (para a pesquisa e como abordagem pedagógica) e outro nas narrativas (para os mesmos fins). Atualmente, alguns de nossos pesquisadores têm preferido se referir apenas à História Oral, considerando não somente que a análise de suas potencialidades pedagógicas e de pesquisa engloba não somente a metodologia e as narrativas que com ela se produz, mas também demarca o modo como essas narrativas foram produzidas.

Como disse Garnica (2014, p. 57), pesquisar em História Oral implica trazer à cena as narrativas, suas potencialidades e suas formas. Por outro lado, se considerarmos a produção dessas pesquisas na Educação Matemática,

[...] talvez fosse mais correto afirmar que o pano de fundo para nossas práticas de pesquisa são as narrativas (não a História Oral) e que, sendo possivel compor essas narrativas de modos distintos, a História Oral tem sido, dentre as tantas possibilidades, o modo mais frequentemente mobilizado.
As narrativas são, assim, o ponto de partida nas compreensões históricas envolvendo História Oral e Educação Matemática. Do mesmo modo, é com elas que buscamos criar nossos discursos sobre as culturas de matemática e educação matemática brasileiras, sobre a formação de professores de matemática no Brasil. Com isto, queremos dizer que há uma escolha, por parte do grupo, em produzir histórias da educação matemática por meio de narrativas. Além disso, por detrás dessa escolha há uma postura política, que se mostra por meio de uma ética e de uma estética. É a narrativa que permite atrelar forma e conteúdo de modo compativel com essa política, essa ética no fazer pesquisa sobre (história da) educação matemática.

A tematização das narrativas no grupo tem, assim, seu início, mais recentemente, por conta da própria movimentação acadêmica e contatos com outros interlocutores. Tanto por esse interesse em investigar as potencialidades metodológicas para pesquisas em (história) da educação matemática, como por analisar as potencialidades da História Oral como abordagem pedagógica no ensino e na formação do professor (de matemática). Os estudos e a teorização sobre as narrativas, em suas várias formas (a oral, as escritas de si, os memoriais de formação, os registros (auto)biográficos), por parte desses pesquisadores, tem crescido ao lado daqueles de outras linhas de pesquisa da área.

Diante do exposto, este texto é um desdobramento das pesquisas em desenvolvimento no grupo e busca tecer compreensões tidas até o momento sobre os movimentos de entrada e circulação das narrativas, no campo da Educação Matemática. ${ }^{3}$ No que se segue, ini-

3 Seguindo os aportes teórico-metodológicos da História Oral, na pesquisa de doutorado de Marinéia dos Santos Silva em desenvolvimento junto ao Programa de Pós-Graduação em Educação Matemática (PPGEM) da Unesp/Rio Claro, estão sendo entrevistados professores-pesquisadores, líderes dos Grupos de Pes- 
ciamos a apresentação deste estudo, a partir de um olhar para o campo (auto)biográfico e a pesquisa narrativa na Educação, para, em seguida, analisarmos os primeiros movimentos de circulação das narrativas na Educação Matemática. Por fim, situamos o movimento da História Oral, como fazendo parte deste movimento mais amplo, que envolve a mobilização das narrativas na Educação Matemática, buscando identificar suas especificidades nesse campo.

\section{Alguns Movimentos (iniciais) da Pesquisa (Auto)biográfica na Educação no Brasil}

O desafio de tecer considerações sobre o movimento (auto)biográfico no Brasil implica, obviamente, riscos de omissões face à sua história, que, embora recente, já se caracteriza por sua diversidade, por um volume considerável de pesquisa, trabalhos e projetos de cooperação científica em âmbito nacional e internacional.

quisa, que trabalham e estudam as narrativas na formação de professores que ensinam Matemática. O critério de escolha dos líderes deu-se por meio de busca no Diretório de Grupos de Pesquisa da Plataforma Lattes - CNPq no campo "grupo de pesquisa", via palavras-chave e expressões como: "narrativas", "narrativas na formação de professores", "narrativas e formação" e, ainda, "narrativas e formação de professores que ensinam Matemática". Além desta busca, a pesquisa também trabalha com o critério de rede - dispositivo usado pelos membros do grupo que, ao entrevistarem um colaborador, este indica outros nomes que poderão contribuir com o objeto de estudo. Todas as entrevistas (oito) já foram realizadas e encontram-se em processo de legitimação por parte dos colaboradores. A partir dessas entrevistas, tivemos acesso a várias obras (incluindo mapeamentos) e textos que nos permitem tecer algumas compreensões sobre o movimento das narrativas em nosso campo. Escolhemos não discutir os resultados advindos das entrevistas, neste texto, sobretudo por estarem em processo de legitimação por parte dos colaboradores. Além disso, este estudo faz parte dos interesses de um projeto de pesquisa maior "Mobilizações de Narrativas na/para a formação inicial de professores de Matemática", em desenvolvimento, cujo objetivo é investigar, elaborar e analisar as potencialidades das narrativas (em suas variadas formas) nos (e para os) espaços voltados à formação de professores (das diversas áreas do conhecimento).
Seria, pois, pretensiosa a intenção de apreendê -lo em sua totalidade. 0 que nos leva a aceitar o desafio é o desejo de mapear seus principais enfoques e possibilidades de explorar o seu interesse para o aprimoramento da pesquisa qualitativa em Educação. (PASSEGGI; SOUZA, 2016, p. 7)

O mapeamento realizado por Marli André (2009, p. 56) acerca da produção acadêmica de teses e dissertações na área da Educação, na década de 1990, com foco na formação de professores, indica que, em 1999, no que se refere aos tipos de estudo "História de Vida, História Oral e Auto-Biografia", havia um total de quatro trabalhos. Esse número avançou para dezessete em 2003, representando cerca de pouco mais de $4 \%$ das teses e dissertações com foco na formação de professores. 0 aumento do número de trabalhos nas pesquisas educacionais que utilizam a escrita de si em processos formativos e de profissionalização docente teve sua consolidação no Brasil a partir da década de 1990, movimento denominado por Passeggi, Souza e Vicentini (2011) de virada biográfica em Educação.

A epígrafe desta seção cita ressalvas de Passeggi e Souza (2016), ao tecerem compreensões sobre o movimento (auto)biográfico no Brasil, dada a sua grande expansão na última década. A discussão dos autores nesse trabalho se dá a partir da apresentação de três pontos: os princípios epistemológicos que norteiam a pesquisa (auto)biográfica brasileira; um breve histórico desse campo, compreendendo o período de 1990-2016; e uma síntese das diferentes edições do Congresso Internacional de Pesquisa (Auto)Biográfica (CIPA), até o realizado em Cuiabá/MT - a última edição naquele momento. Visando o objetivo deste texto, destacaremos a seguir alguns elementos, focando os dois últimos pontos da pesquisa de Passeggi e Souza (2016).

Os autores referem-se a um panorama histórico do Movimento (Auto)Biográfico em 
Educação no Brasil, focando dois períodos: a década de 1990, como sendo um marco inicial das histórias de vida em Educação; e o segundo momento de expansão e diversificação dos temas de pesquisa, iniciado a partir dos anos 2000. Os autores ressaltam que o uso das histórias de vida e de narrativas autobiográficas como metodologia de investigação científica no Brasil, era centrada, inicialmente, na área específica de formação de professores.

Sobre o movimento de entrada das narrativas na Educação, Passeggi, Souza e Vicentini (2011) relatam a contribuição do livro o método (auto)biográfico e a formação, organizado por António Nóvoa e Matthias Finger (1988; 2010), que, no caso brasileiro, inspirou os primeiros trabalhos publicados pelo Grupo de Estudos Docência, Memória e Gênero (GEDOMGE/FEUSP) sobre as histórias de vida e formação.

Para Nóvoa (1995, p. 15, grifos do autor), a publicação do livro "O professor é uma pessoa", de Ada Abraham, em 1984, teve um forte impacto nessa virada autobiográfica em Portugal, pois, para o autor:

A viragem tinha-se iniciado. Desde então, a literatura pedagógica foi invadida por obras e estudos sobre a vida dos professores, as carreiras e os percursos profissionais, as biografias e autobiografias docentes ou o desenvolvimento pessoal dos professores; trata-se de uma produção heterogénea, de qualidade desigual, mas que teve um mérito indiscutivel: recolocar os professores no centro dos debates educativos e das problemáticas da investigação.

António Nóvoa salienta a importância do livro de Ada Abraham, ao chamar a atenção para o momento em que a discussão estava centrada no processo identitário da profissão docente. Para ele, "o movimento nasceu no universo pedagógico, numa amálgama de vontades de produzir um outro tipo de conhecimento, mais próximo das realidades educativas e do quo- tidiano dos professores" (NÓVOA, 1995, p. 19).

Consideramos interessante ponderar o Prefácio da segunda edição do livro "Vidas de Professores", quando Nóvoa fala da publicação do livro organizado por ele e por Mathias Finger:

Em 1988, quando publiquei em colaboração com Matthias Finger $O$ método (auto)biográfico e a formação, as abordagens biográficas eram pouco conhecidas em Portugal e a sua utilização na formação de professores não tinha qualquer significado. Em 1992, aquando da primeira edição de Vida de Professores, a situação já tinha mudado consideravelmente, o que me levou a alertar contra a existência de 'práticas pouco consistentes' e de 'metodologias sem qualquer rigor'. Hoje, em 1995, o aviso deve ser escrito com letras ainda mais cheias. Em sete anos, apenas, muitas coisas se alteraram. Desde logo, no trabalho acadêmico com a aceitação progressiva das perspectivas (auto)biográficas que durante muito tempo estiveram banidas do mundo universitário [...]. (NÓVOA, 1995, p. 7)

Dois pontos significativos são abordados pelo autor. 0 primeiro refere-se ao movimento de expansão das narrativas autobiográficas em Portugal e, o segundo, remete à importância de uma discussão metodológica de consistência nesses trabalhos. Na sequência, Nóvoa (1995, p. 7) reporta-se ao sucesso recente (naquele momento) das abordagens (auto)biográficas como uma vitória, porque "permite[m] a divulgação de olhares novos sobre o trabalho científico e sobre os processos de formação. Mas também uma derrota, pois este sucesso só é possível à custa de algumas das suas características originais, do seu rigor metodológico e das suas dimensões críticas". O autor salienta a importância do fazer científico em termos da realidade escolar e processos formativos na vida docente, e, por outro lado, também evidencia certa preocupação com o rigor teórico-metodológico desses trabalhos, tão importante para aprofundar (ou banalizar) um campo em pleno desenvolvimento. 
Souza (2010) argumenta que, no Brasil, a utilização da história de vida é difundida e influenciada pela História Oral, com o Programa de História Oral do Centro de Pesquisa e Documentação de História Contemporânea do Brasil/Fundação Getúlio Vargas (CPDOC/FGV), na década de 1960. Souza (2010) ainda destaca que, no campo da sociologia, em meados da década de 1970, as pesquisas desenvolvidas pelo Centro de Estudos Rurais e Urbanos (CERU) já eram empreendidas com a utilização da História Oral. Neste contexto, outra instância foi criada em 1994 - a Associação Brasileira de História Oral (ABHO), que, segundo o autor, influenciou a realização de seminários e a divulgação de pesquisas da área.

Passeggi e Souza (2016) relatam que, a partir dos anos 2000, os trabalhos são marcados pela diversificação dos temas de pesquisa dentro do movimento (auto)biográfico. Para os autores, esse segundo momento se torna visível por meio do êxito das edições do CIPA, caracterizando a abertura para as diversas abordagens (para além da formação de professores), contemplando diferentes áreas do conhecimento, como Educação, História da Educação, História, Sociologia, Filosofia, Psicologia, Linguagens e Literatura. Contudo, essa segunda fase da pesquisa (auto)biográfica é marcada:

[...] por reflexões epistemológicas e teórico-metodológicas, objetivando avaliar os avanços das pesquisas com fontes biográficas e autobiográficas em contexto nacional e internacional e fomentar novos direcionamentos. Esse fórum se configura como espaço-tempo para a sistematização da produção científica, de formas de trabalho e lugar em que emergem e se consolidam laços de cooperação e trocas de experiência. A história do CIPA se confunde, portanto, com a expansão e diversificação do movimento (auto)biográfico no Brasil. (PASSEGGl; SOUZA, 2016, p. 17)

Os autores trazem alguns apontamentos sobre as edições do Congresso, sendo a pri- meira realizada em 2004, na cidade de Porto Alegre, organizada pela Pontifícia Universidade Católica do Rio Grande do Sul (PUCRS), até a edição de 2016, realizada em Cuiabá pela Universidade Federal de Mato Grosso (UFMT). Como balanço dessas edições, merece destaque a reunião de pesquisadores de diversos países num fórum de discussão internacional, - lançamento de livros publicados a partir dos textos apresentados e discutidos no Congresso, a participação de grupos de pesquisa vinculados aos programas de pós-graduação pertencentes a diferentes regiões do país. Tais grupos "passam a ter um papel decisivo na construção de redes nacionais e institucionais de pesquisa, fazendo ganhar força as parcerias e cooperação universitária fomentadas antes, durante e depois da realização do Congresso, em torno de uma área então emergente" (PASSEGGI; SOUZA, 2016, p. 17).

Paralelamente às primeiras edições do CIPA, algumas formas de cooperação acadêmica, construídas pela realização de projetos colaborativos e pela participação dos grupos de pesquisa, ${ }^{4}$ e o papel das associações científicas têm permitido expandir os horizontes de intercâmbio interuniversitário no domínio da investigação com histórias de vida e a pesquisa (auto)biográfica em Educação favorecendo aberturas valiosas para a internacionalização da pesquisa nos territórios da lusofonia, francofonia e da hispanofonia (SOUZA et al, 2010).

4 "Apresentaremos dois grupos no Brasil: o Grupo de Pesquisa (Auto)biografia, Formação e História Oral (GRAFHO), vinculado ao Programa de Pós-Graduação em Educação da Universidade do Estado da Bahia (PPGEdUC|UNEB) e o Grupo Interdisciplinar de Pesquisa, Formação, Auto.Bio.Grafia e Representações Sociais (GRIFARS), vinculado ao Programa de Pós-Graduação em Educação da Universidade Federal do Rio Grande do Norte (PPGEd|UFRN); um grupo na França: o Laboratório - Centro de Pesquisas Interuniversitário Experiência, Recursos Culturais, Educação (EXPERICE), vinculado às Universidades de Paris 13|Nord e de Paris 8 e um grupo na Argentina: o Grupo Memória Docente e Documentação Pedagógica, vinculado à Faculdade de Filosofia e Letras da Universidade de Buenos Aires (FFyLIUBA) e ao Laboratório de Políticas Públicas de Buenos Aires (LPP)". (SOUZA et al, 2010, p. 2) 
Para os autores, essas trocas se multiplicam pela ação das associações científicas, como é o caso da Associação Internacional das Histórias de Vida em Formação e da Pesquisa Biográfica em Educação (ASIHVIF), criada em 1991, no contexto da francofonia, e, no caso brasileiro, uma inter-regional - a Associação Norte e Nordeste de Histórias de Vida em Formação (ANNIHVIF), criada em 2006, e uma nacional, criada em 2008, durante Assembleia realizada no III CIPA que é a Associação Brasileira de Pesquisa (Auto)biográfica (BıOgraph5).

A construção e a consolidação da rede de colaboração propiciadas no campo das pesquisas biográficas têm permitido implementar diferentes ações de pesquisa e formação, contemplando quatro vertentes da pesquisa (auto)biográfica como eixos de ação e de investigação.

o primeiro eixo focaliza o ato de narrar como um fenômeno antropológico e civilizatório, que se realiza mediante diferentes sistemas semióticos, notadamente, a linguagem oral e escrita. 0 segundo eixo considera as narrativas autobiográficas como método de investigação, preocupando-se com a constituição e a análise de fontes (auto)biográficas para investigar aspectos históricos, sociais, (multi)culturais, institucionais da formação e da profissionalização docente. 0 terceiro toma as narrativas de si como prática de (auto)formação, procurando investigar as atividades auto-reflexivas e suas repercussões na formação e inserção na vida profissional. Considerando que as práticas de formação implicam formandos e formadores, o quarto eixo investiga o uso das narrativas autobiográficas como procedimento de intervenção educativa, focalizando a formação docente para o acompanhamento das escritas de si. (SOUZA et al, 2010, p. 9)

5 Que tem como objetivos reunir pesquisadores brasileiros "que pesquisam (auto)biografias, memória, histórias de vida e práticas de formação, bem como promover e coordenar estudos e pesquisas, eventos e ensino no âmbito da pesquisa (auto)biográfica, a partir de um diálogo com associações congêneres, especialistas nacionais e internacionais e desenvolver ações interdisciplinares no campo de pesquisa-ensino". (SOUZA et al, 2010, p. 8).
Para os autores, o trabalho desenvolvido pela rede de colaboração tem possibilitado um diálogo frutífero em torno da pesquisa (auto)biográfica, considerando as aproximações teóricas e as experiências de formação de cada um dos pesquisadores, em suas distintas vertentes de pesquisa, nos contextos latino-americano e europeu. Com esse espírito, embora com nomenclatura e fundamentações distintas, podemos dizer que a História Oral também tem sua atuação (não somente como metodologia de pesquisa), em várias áreas das ciências humanas, e possui motivações similares às apresentadas no segundo e terceiros eixos citados.

Outro espaço de circulação e propagação das ideias foi criado no CIPA, em 2016, onde foi lançado o primeiro número da Revista Brasileira de Pesquisa (Auto)biográfica (RBPAB) da BIOgraph, sendo, portanto, um periódico científico especializado na área de conhecimento com fontes (auto)biográficas (PASSEGGI; SOUZA, 2016).

Ao longo dos últimos doze anos [...] o CIPA vem reunindo, a cada dois anos, um número cada vez mais significativo de pesquisadores de diferentes nacionalidades e de diversas áreas do conhecimento para participar, no Brasil, deste fórum de discussão com o objetivo de colaborar para os avanços do movimento (auto)biográfico do ponto de vista nacional e internacional e pensar os seus desafios. O Congresso, que se inscreve como uma iniciativa acadêmico-científica, constitui um espaço privilegiado de partilha de conhecimentos e de democratização de saberes decorrentes de pesquisas, fomentando a cooperação internacional, pesquisas e práticas de formação que têm, nas narrativas biográficas e autobiográficas, seu campo de inserção, atuação e sua centralidade. (PASSEGGl; SOUZA, 2016, p. 22)

Percebemos, portanto, nesse estudo, a importância da formação de redes de cooperação entre os pesquisadores de diferentes países, sobretudo a criação de associações, grupos de 
pesquisa e congressos, por fomentarem a pesquisa no campo (auto)biográfico e de pesquisa narrativa (inter)nacionalmente. Entendemos alguns dos movimentos de entrada e circulação propriamente no território brasileiro, sobretudo, na área de Educação. Neste contexto, veremos, a seguir, como os movimentos da pesquisa (auto)biográfica iniciam ou migram para a Educação Matemática.

\section{Movimentos de pesquisas envolvendo narrativas na Educação Matemática}

Como vimos, Passeggi e Souza (2016) tratam anteriormente de dois momentos decisivos da pesquisa (auto)biográfica no Brasil. O segundo deles caracterizado pela diversidade de estudos na formação de professores e também a entrada da pesquisa (auto)biográfica em outras áreas do conhecimento, o que inclui a Educação Matemática.

Sobre o processo de circulação das narrativas neste campo, o livro "Mapeamento da pesquisa acadêmica brasileira sobre o professor que ensina matemática: período 2001-2012",6 aponta que a entrada da pesquisa (auto)biográfica na Educação Matemática começou a ganhar espaço no Brasil, particularmente no início dos anos 2000, denotando uma nova perspectiva de pesquisa sobre o professor que ensina Matemática (NACARATO et al, 2016).

Nacarato, Oliveira e Fernandes (2017) fazem apontamentos sobre dois dos múltiplos

6 Este e-book faz parte do Projeto: "Mapeamento da pesquisa acadêmica brasileira sobre o professor que ensina Matemática: período 2001 - 2012" (CNPq/Processo 486505/2013-8), coordenado pelo Grupo de Estudos e Pesquisas sobre a Formação de Professores que Ensinam Matemática (GEPFPM). Esse projeto teve por objetivo mapear, descrever e sistematizar as pesquisas brasileiras que têm como foco de estudo o professor que ensina Matemática (PEM), produzidas no período de 2001 a 2012, em Programas de Pós-Graduação Stricto Sensu das áreas de Educação e Ensino da Coordenação de Aperfeiçoamento de Pessoal de Nivel Superior (Capes). focos temáticos identificados nos estudos provenientes do Projeto Mapeamento, discutindo dois deles - a "História da formação do professor que ensina Matemática" e "História do professor que ensina Matemática". Com um conjunto de 45 trabalhos, distribuídos entre dissertações e teses, as autoras buscaram identificar as abordagens metodológicas e os referenciais teóricos utilizados e constatar se as pesquisas que focam nas histórias de professores que ensinam Matemática se aproximam dos estudos biográficos. Deste modo, as autoras identificaram "que a aproximação entre eles [os dois focos] vai além da questão metodológica: as vozes do sujeito professor e o seu protagonismo na construção da história da Educação Matemática constituem o fulcro dessa proximidade" (NACARATO; OLIVEIRA; FERNANDES, 2017, p. 66).

O estudo também aponta, segundo as autoras, que a História Oral se constitui como uma abordagem metodológica para as histórias de vida de professores. Nessa perspectiva, há um destaque para as pesquisas do Grupo História Oral e Educação (Ghoem) vinculadas ao uso de análise (narrativa) de narrativas na/ para a História da Educação Matemática.

Outra influência apontada nos trabalhos identificados nessa modalidade é a presença de trabalhos orientados pela pesquisadora Terezinha Valim Oliver Gonçalves da Universidade Federal do Pará (UFPA). Este fato é apontado, pois a professora Terezinha realizou sua pesquisa de doutorado tendo como foco a pesquisa narrativa no final da década de 1990 e, desde então, vem desenvolvendo pesquisas e orientando trabalhos na área de Ciências e, por vezes, na formação de professores que ensinam Matemática (NACARATO; OLIVEIRA; FERNANDES, 2017).

Sem dúvida, há muitos desafios para o campo das pesquisas sobre histórias de formação e de vida, independente das abordagens metodoló- 
gicas utilizadas. São pesquisas que não apenas escutam os professores, mas também buscam por sentidos e significados das experiências vividas. [...] Esse respeito e essa honestidade de linguagem, presentes nos trabalhos aqui analisados, precisam continuar sendo a marca das pesquisas em Educação Matemática que tomam como objeto de análise as histórias de formação ou as histórias de professores. (NACARATO; OLIVEIRA; FERNANDES, 2017, p. 67)

Um elemento significativo de propagação e interlocuções deste campo na Educação Matemática é também a participação do professor-pesquisador Elizeu Clementino de Souza, como um dos responsáveis por abrir espaço para a Educação Matemática no CIPA. Isso porque há um reconhecimento deste pesquisador, por parte dos educadores matemáticos, como um dos maiores estudiosos no campo das narrativas no Brasil. Um indício de tal reconhecimento foi o convite que Elizeu recebeu para participar da 32a Reunião Anual da Associação Nacional de Pós-Graduação e Pesquisa em Educação (Anped), em 2009, como pesquisador externo para discutir os textos no Grupo de Trabalho (GT19) de Educação Matemática, tendo como tema as narrativas. Vale ressaltar que o conjunto desses trabalhos apresentados no GT constituiu no que é considerado o primeiro dossiê brasileiro na interface Narrativas e Educação Matemática.

No texto introdutório desse dossiê, Souza (2010) apresenta, por meio de uma tabela, os autores, as instituições, os grupos de pesquisa, os métodos de investigação, instrumentos de coleta, os colaboradores da pesquisa e as formas de análise dos oito trabalhos. 0 autor ressalta a participação dos seguintes grupos de pesquisa que são interinstitucionais: o Grupo de Estudo e Pesquisa sobre Formação de Professores de Matemática (GEPFPM), Grupo História Oral e Educação Matemática (GHOEM) e o Grupo Interdisciplinar de Pesquisa, Formação, AutoBiografia, Representações e Subjetivi- dade (GRIFARS), cujas sedes, respectivamente, estão na Universidade Estadual de Campinas (UNICAMP), Universidade Estadual Paulista "Júlio de Mesquita Filho" (UNESP) e Universidade Federal do Rio Grande do Norte (UFRN).

Ao contemplar essa coletânea de trabalhos, Souza (2010) analisa e discute os três eixos centrais gerados: a pesquisa narrativa, narrativas autobiográficas e história oral e ressalta os modos próprios de trabalho no que se refere às pesquisas e às práticas de formação com História Oral e Educação Matemática:

O que há em comum entre estes textos? Primeiro, a identificação do modo como os pesquisadores propõem o trabalho de formação através das narrativas orais e das proposições de escritas de si como dimensão de formação inicial ou continuada. As especificidades nacionais possibilitam aos pesquisadores inventarem modos de trabalhos que guardam em si aproximações, vizinhanças e distâncias, o que não significa fragilidade teórica ou metodológica. Pelo contrário, explicitam perspectivas de verticalização do trabalho de pesquisa com as narrativas, a História Oral e as práticas de formação em Educação Matemática, resguardando o espaço-tempo acadêmico em que cada trabalho foi produzido. (SOUZA, 2010, p. 23)

No ano seguinte ao evento da Anped, Elizeu convidou alguns educadores matemáticos para apresentar seus trabalhos por meio de uma mesa redonda.' Este fato evidencia, assim, um reconhecimento de Elizeu Clementino de Souza à Educação Matemática como sendo uma das áreas que tem contribuído para a discussão e disseminação do movimento (auto) biográfico no Brasil.

Notamos assim, que é a partir de então, que se intensifica a propagação da pesquisa com as narrativas na área da Educação Matemática. Até o momento há quatro dossiês te-

7 NACARATO, A. M.; PASSOS, C. L. B.; GARNICA, A. V. M. Narrativas (auto)biográficas: artes de conhecer como professores de matemática se constituem profissionalmente (IV CIPA). 2010. (Mesa Redonda) 
máticos na interface - Narrativas e Educação Matemática. O primeiro deles, advindo desse evento da Anped, foi publicado na revista Ciências Humanas e Sociais, da Universidade Federal Rural do Rio de Janeiro (UFRRJ), em 2010, e organizado por Elizeu Clementino de Souza e Adair Mendes Nacarato. A segunda edição temática foi organizada por Cármen Lúcia Brancaglion Passos e divulgada no periódico Interacções em 2011, da Revista da Escola Superior de Educação de Santarém, Portugal. Em 2013, outro dossiê, da Revista Educação da PUC/Campinas, foi organizado por Adair Nacarato e Cármen Passos, denominado "Escritas, narrativas \& formação docente em Educação Matemática". A última edição temática (até o momento) "Narrativas na pesquisa em Educação Matemática" foi publicada pelo Boletim de Educação Matemática (BOLEMA), em 2014, tendo como editoras convidadas: Adair Nacarato, Cármen Passos e Heloisa da Silva.

Em Silva e Silva (2018), fazemos alguns apontamentos a partir dos textos introdutórios do primeiro e quarto dossiês (SOUZA, 2010; NACARATO; PASSOS; SILVA, 2014). No primeiro caso, o autor trata de algumas aproximações e possiveis distanciamentos entre a pesquisa narrativa, as (auto)biografias, a história oral e as práticas de formação em Educação Matemática, no que se refere aos modos próprios de trabalho com as narrativas empreendidas pelos grupos de pesquisa em Educação Matemática e no âmbito da pós-graduação em Educação. Já no quarto dossiê, as autoras tratam, sobretudo, da polissemia envolvendo a palavra narrativa, que para elas se constitui de diversos modos:

[...] escrita do professor, narrativas (auto)biográficas, narrativas da experiência, histórias de vida, memoriais de formação, narrativas e/ ou trajetórias de formação, narrativas de aulas, pesquisa narrativa e investigação biográficonarrativa. Em muitos casos, não se trata de termos correlatos, mas com múltiplos significados e múltiplas formas de abordagem teórica e de análise. (NACARATO; PASSOS; SILVA, 2014, p. 702)

Percebemos ao longo dos nossos estudos que, por se tratar de uma tendência emergente (as narrativas) na Educação Matemática, alguns trabalhos nesse campo não fazem parte de mapeamentos realizados, como ressaltam (NACARATO et al, 2016) e (NACARATO; OLIVEIRA; FERNANDES, 2017). Tais pesquisas também apontam o aumento do número de pesquisas realizadas após o período de 2001-2012, em que grupos de pesquisa passam a tematizar, discutir e publicar trabalhos na interface Narrativas e Educação Matemática.

Deste modo, podemos salientar que alguns espaços que não constam em mapeamentos anteriores é, por exemplo, o caso do grupo de pesquisa Histórias de Formação de Professores que Ensinam Matemática (HIFOPEM), criado em 2010, junto ao Programa de Pós-Graduação em Educação da Universidade São Francisco, tendo como líder Adair Mendes Nacarato. Em uma recente publicação, ${ }^{8}$ que trata de aspectos teóricos e metodológicos de pesquisas em Educação Matemática, o Grupo de Pesquisa HIFOPEM aborda sua trajetória ao longo dos anos e a constituição de um caminho teóricometodológico de abordagem das narrativas. Participam deste grupo alunos de mestrado, doutorado, pós-doutorado e egressos do Programa que continuam no grupo. Deste modo, o grupo é criado para estudar e analisar pesquisas que têm como centro as narrativas, em suas diversas perspectivas:

Desde o início, temo-nos dedicado a estudar e analisar pesquisas que tomam como foco as narrativas, em suas múltiplas perspectivas: narrativas de práticas, narrativas de vida, narrativas de trajetórias e pesquisa narrativa. Os

8 In: OLIVEIRA, Andréia Maria Pereira de.; ORTIGÃO, Maria Isabel Ramalho. (Orgs.). Abordagens teóricas e metodológicas nas pesquisas em Educação Matemática. Brasília, DF: SBEM, 2018. v. 1, p. 90-112. (Coleção SBEM, 13). 
estudos têm sido desenvolvidos com professores de diferentes níveis de ensino, bem como com estudantes do Ensino Fundamental, Médio e Superior. A Educação Matemática tangencia ou perpassa a maioria das pesquisas. (GRUPO DE PESQUISA HIFOPEM, 2018, p. 90)

Em seguida, os autores trazem discussões sobre os referenciais teóricos (inter)nacionais, as metodologias de produção e a análise dos dados nas pesquisas que permeiam os afazeres do grupo. Os autores remetem aos avanços do grupo, no que tange ao estudo das narrativas, prioritariamente com a entrevista narrativa, e os grupos de discussão-reflexão, e fazem uma ressalva sobre o compromisso ético nas pesquisas de seu grupo e, por último, falam dos limites desse campo de investigação ponderando que é preciso avançar nos processos analíticos e na produção de "textos menos híbridos - aqueles que combinam análise categorial com modo narrativo de análise - e assumindo, de fato, a análise narrativa, sem perder de vista o rigor e a consistência da investigação" (GRUPO DE PESQUISA HIFOPEM, 2018, p. 108).

Coordenado também por Adair, o Grupo Colaborativo em Matemática (Grucomat ${ }^{9}$ ) foi criado no início dos anos 2000 e é vinculado ao Programa de Pós-Graduação em Educação da Universidade São Francisco, campus Itatiba/SP. Desde então, vem corroborando para o desenvolvimento e fortalecimento das narrativas na Educação Matemática, com a publicação de livros, artigos e capítulos nesta seara.

9 O grupo tem como objetivos: 1) construir um referencial teórico-metodológico sobre os processos formativos dos professores que ensinam matemática, principalmente quando esses participam de grupos de trabalho de dimensão colaborativa ou de comunidades de investigação; e 2) produzir colaborativamente um repertório de tarefas e investigações em sala de aula de matemática, visando à construção de uma cultura de aula de matemática problematizadora. Vale ressaltar que o grupo já desenvolveu três projetos aprovados pelo Universal/CNPq, com temas centrados em: geometria, estocástica e raciocínio algébrico. Fonte: Diretório dos Grupos de Pesquisa no Brasil do CNPq. Disponivel em: <http://dgp.cnpq.br/ dgp/espelhogrupo/204580>. Acesso em: 31 mar. 2019.
Quem participa deste espaço são professores do ensino básico da região de Campinas/SP, alunos de pós-graduação e professores que atuam na Universidade São Francisco, e dentre outros afazeres, os participantes discutem e escrevem sobre suas práticas no que se refere ao ensino e aprendizagem de Matemática.

Outro grupo de pesquisa na Educação Matemática, que passou a desenvolver pesquisas na interface "Narrativas e Educação Matemática", é o Grupo de Estudos e Pesquisa em Educação Matemática (GEM), cadastrado no Diretório de Grupos de Pesquisa do CNPq em 2004. Este grupo é coordenado por Cármen Lúcia Brancaglion Passos e sua sede fica junto a Universidade de Federal de São Carlos (UFSCar). Passos et al (2018) tecem considerações sobre os temas de interesse do grupo desde sua criação até chegarem às escritas narrativas, fortalecidas pelos estudos (auto)biográficos e pesquisas no campo da formação de professores que ensinam matemática. Na sequência do trabalho, os autores apresentam a ampliação do foco de investigação, quando as narrativas de formação passaram a dar lugar a outros estudos e debates no GEM e reverberaram em pesquisas que utilizavam narrativas para a produção de dados. Assim, as pesquisas do GEM passaram a incorporar metodologias da pesquisa narrativa nos seus estudos e investigações:

São assim trazidos para o GEM, além dos textos de Bruner, outros autores como Galvão (1998, 2005); Conelly e Clandinin (1990); Josso (2002) sobre pesquisa narrativa. Desde então, o grupo tem estudado e se apoiado, metodologicamente, nas narrativas como modo de produção de dados, como ferramenta de formação de professores e, mais recentemente, como um método de produção de pesquisa. Assim, os dados de dissertações de mestrado e doutorado mais recentes, desenvolvidas no GEM, têm optado pela natureza narrativa da pesquisa, em que o professor participante é convidado a narrar experiências vividas, sentimentos, visões, concepções, em que refletem sobre si, projetam 
expectativas, revivem a formação e a própria atuação enquanto professor que ensina matemática. (PASSOS et al, 2018, p. 220)

Ressaltamos, também, o grupo de pesquisa GEPFPM, ${ }^{10}$ coordenado por Dario Fiorentini já apontado anteriormente por Souza (2010), que trabalha especificamente com temas voltados para a formação de professores que ensinam Matemática.

O Grupo de Estudos e Pesquisas sobre Formação de Professores de Matemática (GEPFPM) foi criado, em 1999, por iniciativa de mestrandos e doutorandos da Área de Educação Matemática da FE/Unicamp, motivados pela necessidade de realizarem estudos, tendo em vista o desenvolvimento de pesquisas sobre formação e desenvolvimento profissional de professores de matemática. Este grupo passou, depois, a ser institucionalizado como subgrupo do Grupo de Pesquisa sobre Prática Pedagógica em Matemática (PRAPEM) da FE/UNICAMP, tendo como coordenador geral o professor Dario Fiorentini (FE/Unicamp). Mais tarde, entretanto, à medida que seus participantes concluíram o doutorado e passaram a atuar como docentes em instituições próximas à Campinas, o grupo tornou-se um grupo de pesquisa independente e interinstitucional. (GRUPO GEPFPM, 2018, p. 235)

Além do PRAPEM e do GEPFPM, Dario também coordena o Grupo de Sábado (GdS) (que mesmo não sendo cadastrado via Diretório de Grupos de Pesquisa do CNPq), surge em 1999 e, desde então, o grupo vem tematizando as narrativas na formação de professores que ensinam Matemática. O GdS congrega professores de Matemática do Ensino Fundamental e Médio e alguns alunos de mestrado e doutorado da Faculdade de Educação da Unicamp. O grupo se reúne aos sábados de manhã, para estudar, compartilhar, discutir e escrever sobre a prática pedagógica em Matemática. A produção do

10 Os autores salientam que "este é o nome original e oficial do grupo, como consta cadastrado no CNPq, mas estamos em processo de alteração para: “Grupo de Estudo e Pesquisa sobre Formação de Professores que Ensinam Matemática", mantendo a sigla original GEPFPM". (GEPFPM, 2018, p. 234) grupo está divulgada por meio de artigos científicos, teses, dissertações e livros, onde algumas dessas publicações são as narrativas dos professores participantes desse grupo. Dario Fiorentini esporadicamente orienta trabalhos com o viés narrativo em seus grupos de pesquisa (FIORENTINI; MEGID, 2010; CRISTOVÃO; FIORENTINI, s.d.; FREITAS; FIORENTINI, 2008) e recentemente vem desenvolvendo estudos com análises narrativas (CRECCI; FIORENTINI, 2014; LOSANO; FIORENTINI; VILLARREAL, 2017; LOSANO; FIORENTINI, 2018).

Outro espaço que desenvolve pesquisas tendo as narrativas como matéria-prima para os trabalhos é o Ghoem, coordenado por Antonio Vicente Marafioti Garnica e já apontado nos trabalhos de Souza (2010) e Nacarato, Oliveira e Fernandes (2017). Como afirmamos, esse grupo vem mobilizando as narrativas por meio da História Oral em suas pesquisas há duas décadas, mas sua criação oficial junto ao Diretório de Grupos de Pesquisa do CNPq foi no ano de 2002. Tal grupo tem como principal interesse a produção de fontes históricas, a partir de entrevistas, sob a abordagem da História Oral e a tessitura de compreensões sobre as culturas de matemática e educação matemática brasileiras, em especial, sobre a formação de professores de Matemática, principalmente sob um viés histórico. Já tecemos algumas considerações sobre este grupo, ao longo do texto, mas reservamos o item que se segue para pontuarmos as principais motivações e fundamentações desse grupo, bem como o movimento de tematização das narrativas em seu interior.

\section{Os primeiros movimentos da História Oral na Educação Matemática e as narrativas no Ghoem}

Desde 1999, Garnica vem discutindo e orientando pesquisas que têm como foco a História 
Oral como metodologia de pesquisa. Segundo ele:

É a partir de narrativas que criamos nossos discursos (nossas narrativas) sobre a formação e a atuação de professores de Matemática. As narrativas não são meramente manifestação de práticas ou vetores para que uma história possa ser comunicada, mas inventoras de práticas: as narrativas criam realidade enquanto comunicam. Apostar na metodologia da História Oral é um modo de efetivar essas disposições, já que, segundo essa abordagem, as narrativas orais, registradas em momentos de entrevista, são as matérias-primas por excelência de todo um processo hermenêutico que entretanto, não dispensa narrativas outras, como, por exemplo, as escritas. (GARNICA, 2014, p. 58)

Quanto às motivações do movimento de entrada da História Oral na Educação Matemática, num primeiro inventário dos trabalhos em História Oral desenvolvidos na área, Garnica (2006) fez sugestões sobre o papel que a interface História Oral e Educação Matemática poderia desempenhar nas discussões envolvendo a formação de professores de Matemática:

Concepções e práticas, sabemos, são termos visceralmente interligados: há uma retro-alimentação entre práticas e concepções. Concepções alimentam-se das práticas e nessas práticas são explicitadas e rearticuladas, gerando/ reforçando concepções. 0 estudo das práticas de atuação e de formação de professores, portanto, parece ser ingrediente fundamental a ser discutido em um espaço cujo objetivo precípuo é a formação de professores que transitará por práticas/concepções muitas delas já estabelecidas e, portanto, confortáveis, exigindo reavaliação. 0 estudo das práticas, portanto, será tão mais eficiente quando feito a partir de sujeitos concretos, próximos, sejam eles atores do processo escolar (professores, alunos, administradores, pais, mães, vizinhos, amigos), sejam eles atores excluídos desse processo. Entender os mecanismos de inclusão e exclusão do sistema escolar; atentar para momentos de formação que ocorrem fora da escola; conhecer as for- mas de gerenciamento e avaliação (passadas e presentes) dos chamados 'sistemas de ensino'; re-constituir abordagens didáticas para auscultar seus fundantes pedagógicos; compreender como, historicamente, foram se desenvolvendo os processos de formação de professores (e alunos), conhecer - a partir de concepções passadas e presentes - a constituição da Educação Matemática (que como região de inquérito preenche o próprio espaço da formação de professores) etc, devem, nesse contexto, ser focos prioritários. A História Oral como metodologia de pesquisa qualitativa pode, nesse aspecto, desempenhar papel fundamental por focar sujeitos concretos e próximos ao contexto dos estudantes (o que permite ao estudante perceber que as práticas tratadas não estão no âmbito de uma abstração que the é distante e alheia). Concebendo como elementos de abstração as teorias pedagógicas, os métodos didáticos, os aspectos filosóficos, políticos e axiológicos da Educação e da Educação Matemática, as atividades em História Oral e Educação Matemática poderão articular, por exemplo, as disciplinas classicamente conhecidas como 'disciplinas pedagógicas' às situações concretas, visando a buscar, ao longo da formação inicial, a tão decantada articulação teoria-prática. Além disso, a História Oral permite uma reconfiguração da concepção clássica de História (incluindo nisso, a desestabilização da História como 'estudo do passado' e instrumento de heroificação). Nessas 'atividades', entretanto, deve-se tratar não só de um conjunto de procedimentos, mas de seus fundamentos e das compreensões por eles (procedimentos e fundamentação) possibilitadas, situando o estudante num panorama do qual ele é a realização presente, motivando a compreensão dos fios a partir dos quais são tecidas suas práticas/concepções acerca do que é ser professor, de quais concepções e práticas a formação tem se nutrido e de como, quando necessário, implementar formas alternativas de ação. (GARNICA, 2006, p. 158-159)

É importante frisarmos que, além do papel utilitário dessas pesquisas em processos voltados à formação de professores (de Matemática), destacado pelo autor nesse trecho, ele também se refere a um aspecto mais abran- 
gente e, diríamos, importante nessa iniciativa, que é a circulação dessas várias narrativas na discussão e compreensão dos aspectos que envolvem a profissão do professor (de Matemática) e de como essa medida permite, por sua vez, um posicionamento dos futuros profissionais como atores sociais envolvidos nesse processo histórico.

A História Oral na Educação Matemática surge, assim, a partir de um movimento de educadores matemáticos que não apenas se identificam como tal, mas cujos questionamentos e interesses os colocam nesse lugar, o de educadores matemáticos e não propriamente de historiadores (da educação). O interesse pelo viés histórico surge mediante uma busca por compreensões de aspectos da educação matemática brasileira, escolar ou não, seus percalços, visando processos voltados à formação de professores de Matemática, ou seja, a contribuição dessas compreensões para esses processos. Já o interesse pela metodologia da História Oral, que por sua vez determina o teor e a política por detrás da produção historiográfica, parece ter surgido por uma vontade e sensibilidade de trazer à cena um conhecimento produzido a partir de testemunhos e experiências pessoais ou atores sociais envolvidos com a educação (matemática) - sobretudo professores -, seus regimes de verdade, as diferentes perspectivas e aspectos que os envolvem, a possibilidade de entender centros e margens, as condições variadas em que se deram/dão suas vidas, suas (trans)formações e suas performances e relações com a matemática e a educação matemática nas diversas regiões do país, de como seguiam/seguem ou subvertiam/subvertem as legislações, os sentidos que deram/dão a esses aspectos, dentre outras disposições vigentes (GARNICA, 2013).

Vemos assim, que existe uma política (de narratividade) a embasar as pesquisas desse grupo, cuja motivação se inicia em uma con- traposição ao silenciamento de pessoas ditas "comuns" que, de um modo geral, tem operado por vias da historiografia e da Ciência no Brasil como um projeto político a ser desafiado e termina em uma divulgação dessas narrativas como se por meio de megafones, com a intenção precípua, de quem sabe, fazer ecoar essas histórias em ações futuras, em algum lugar (SOUZA, 2018).

A narrativa tem sido um modo de contar uma história frente a alguém, e assim, ela pode se dar a partir do oral, do escrito, de imagens, de contos, de músicas, entre outras formas de fazeres, como maneiras de nos constituirmos/ estarmos/sermos no mundo (GARNICA; SOUZA, 2012). Esse narrar-se frente a alguém é o que constitui o sujeito como ser histórico e cognitivo na direção desse alguém. Sobre esse processo, Albuquerque Jr (2011, p. 254) explica:

[...] o homem que se conta não é o mesmo homem que vive, mesmo quando narra sua própria vida. Quando faz memória ou autobiografia, o sujeito narrador não coincide com o sujeito narrado, o sujeito da narrativa não é o mesmo personagem contado. Porque o sujeito da narrativa é um sujeito em estado de vida, em carne e osso, é um sujeito em que corre sangue nas veias. Já o sujeito narrado é um sujeito em estado de palavra, é feito de papel, é um sujeito em que corre tinta nas veias. 0 historiador que pretende estar falando do sujeito de carne e osso, falará na verdade do sujeito de papel e tinta que chega até ele mediante suas distintas formas de representação, embora estas formas de representação permitam a ele, pelo menos, garantir que o seu personagem realmente fez parte do passado. 0 historiador dará a ele uma nova vida, de tinta e papel, embora faça parte do pacto de leitura entre o leitor e o autor do texto historiográfico acreditar que ali se fala do sujeito de carne e osso que um dia viveu no passado.

\section{E Bruner (2014, p. 96):}

[...] é através da narrativa que nós criamos e recriamos a individualidade; que o eu é produto 
de nosso contar, e não uma essência a ser perscrutada nos recônditos da subjetividade. Nos dias de hoje existem evidências de que, se nos faltar a capacidade de fabricar histórias sobre nós mesmos, não existirá uma coisa como a individualidade.

É também por uma postura de pesquisa e história, que nega a existência de uma verdade única e essencial e a neutralidade de quem produz e relata uma pesquisa/uma história, que as compreensões tecidas a partir das pesquisas realizadas no Ghoem têm se dado por meio das narrativas ou análises narrativas de narrativas (BOLIIVAR; DOMINGO; FERNÁNDEZ, 2001). Esta postura visa a construção de uma história em que estão articuladas as histórias constituídas com os entrevistados durante a pesquisa, bem como as indicações de fontes outras, com o objetivo de compreender singularidades e a possibilidade de coexistência de diferentes perspectivas.

Como dissemos anteriormente, essa perspectiva analítica ou essa forma de tecer as compreensões sob um viés histórico, tem se mostrado potente no sentido de amalgamar forma e conteúdo, evidenciando a singularidade do próprio pesquisador ao propor, desenvolver e comunicar sua pesquisa, bem como a ocorrência simultânea de múltiplas histórias, de diferentes sensibilidades de mundo. Uma pesquisa que, ao mesmo tempo em que demonstra imparcialidade por evidenciar as diferentes versões históricas, apresenta também uma parcialidade ao expor sua própria versão histórica, está promovendo a diferença, evidenciando a diversidade e, diante disso, constitui-se, de tal forma, engajada politicamente em ações não colonizadoras, ao não impor uma história como única. Por essas razões, em pesquisas nessas perspectivas há a mobilização do plural: matemáticas, histórias, matemáticas modernas, Pibids, ${ }^{11}$ entre outros.

11 O Programa Institucional de Bolsas de Iniciação à Docência (Pibid) é uma ação da Política Nacional de
Apontamentos gerais sobre os movimentos das narrativas na
Educação Matemática

Por meio dos movimentos apresentados, percebemos que o crescente número de abordagens sobre as narrativas na Educação Matemática e, mais especificamente, na formação de professores que ensinam Matemática indica um avanço de perspectivas sendo estudadas nesse campo. Os grupos de pesquisa, as associações, os congressos e os trabalhos científicos desenvolvidos pelos Programas de PósGraduação na área da Educação Matemática são espaços significativos que corroboram a produção, a disseminação e o fortalecimento das narrativas na Educação Matemática.

Observamos a complexidade e a heterogeneidade de temáticas na constituição do campo (auto)biográfico, segundo nossos entendimentos iniciais feitos por meio de leituras sobre a área. Para Souza (2010, p. 23):

[...] a diversificação terminológica apresentadas nos textos destacam modos de trabalhos centrados na oralidade e na escrita em uma perspectiva colaborativa através da análise teórico

Formação de Professores do Ministério da Educação (MEC) que visa proporcionar aos discentes, na primeira metade do curso de licenciatura, uma aproximação prática com o cotidiano das escolas públicas de educação básica e com o contexto em que elas estão inseridas. O programa concede bolsas a alunos de licenciatura participantes de projetos de iniciação à docência desenvolvidos por instituições de educação superior (IES) em parceria com as redes de ensino. Disponivel em: <http://www.capes.gov.br/educacao -basica/capespibid/pibid>. Acesso em: 31 mar. 2019. 0 primeiro edital desse Programa foi lançado em 12 de dezembro de 2007, por iniciativa do MEC, por intermédio da Secretaria de Educação Superior (SESU), da Coordenação de Aperfeiçoamento de Pessoal de Nível Superior (Capes) e do Fundo Nacional de Desenvolvimento da Educação (FNDE). Mais informações podem ser encontradas nos seguintes trabalhos desenvolvidos no Ghoem: ver Zaqueu (2014). E também em duas teses (ZAQUEU-XAVIER e TIZZO) que foram publicadas em 2019 e que discutem as narrativas no Pibid. Esses trabalhos foram orientados pela professora Heloisa da Silva e os dois últimos fazem parte do Projeto "Mobilizações de Narrativas na/para a formação inicial de professores de Matemática" em desenvolvimento, coordenado por ela junto ao CNPq. 
-prática dos processos constitutivos da identidade docente e dos saberes de professores de matemática.

Neste sentido, Nacarato et al (2014) também apontam a mesma dispersão terminológica encontrada nos dossiês anteriores (2010, 2011 e 2014), onde estavam presentes as "histórias de vida, história oral, narrativas de aula, escritas de si, memoriais de formação, diários de formação, dentre outros. Entendemos ser essa a riqueza de nossa área ao possibilitar olhares para os contextos de sala de aula e de formação docente sob múltiplas perspectivas" (NACARATO; PASSOS; SILVA, 2014, p. 704-705).

Para além da diversidade de temas apontados no que tange às narrativas sobre a formação de professores que ensinam Matemática, viemos pontuar o lugar da História Oral que desenvolve estudos e trabalhos na Educação Matemática, uma vez que a História Oral com seus aportes teórico-metodológicos corrobora a disseminação e o fortalecimento do movimento das narrativas na Educação Matemática.

\section{Referências}

ABRAHAM, Ada. L'enseignant est une personne. Paris: ESF. 1984.

ALBUQUERQUE JÚNIOR, Durval Muniz de. Em estado de palavra: quando a história não consegue que se meta fora a literatura. In. Flores, M. B. R.; Piazza, M. F. F. (Orgs.). História e arte: movimentos artísticos e correntes intelectuais. Campinas, SP: Mercado de Letras, 2011. p. 249-261.

ANDRÉ, Marli Eliza Dalmazo Afonso de. A produção acadêmica sobre formação de professores: um estudo comparativo das dissertações e teses defendidas nos anos de 1990 e 2000. Revista Brasileira de Pesquisa sobre Formação Docente, Belo Horizonte, v. 1, n. 1, p. 45-56, ago./dez. 2009.

BARTHES, Roland et al. Análise estrutural da narrativa. Tradução de Maria Zélia Barbosa Pinto. Introdução à edição brasileira por Milton José Pinto. 7. ed. Petrópolis, RJ: Vozes, 2011.

BOLÍVAR, Antonio.; DOMINGO, Jesús.; FERNÁNDEZ, Manuel. La investigación biográfico-narrativa en educación: enfoque y metodología. Madri: Editorial La Muralla S.A., 2001.

BRUNER, Jerome. Fabricando histórias: Direito, Literatura, Vida. Tradução de Fernando Cássio. São Paulo: Letra e Voz, 2014. (Coleção Ideias).

CRECCI, Vanessa Moreira. FIORENTINI, Dario. Um professor escolar em uma comunidade investigativa - análise narrativa de seu desenvolvimento profissional. Linha Mestra (Associação de Leitura do Brasil), v. 24, p. 3305-3310, 2014.

CRISTOVÃO, Eliane Matesco; FIORENTINI, Dario. Histórias e investigações de/em aulas de Matemática. Campinas, SP: Editora Alínea, s.d.

FREITAS, Maria Teresa Menezes; FIORENTINI, Dario. Desafios e potencialidades da escrita na formação docente em matemática. Revista Brasileira de Educação, v. 13, p. 138-149, 2008.

FIORENTINI, Dario; MEGID, Maria Auxiliadora Bueno Andrade. Autobiografias e narrativas de aprendizagem. In: KLEINE, M. U.; MEGID NETO, J. (Orgs.). Fundamentos de Matemática, Ciências e Informática para os Anos Iniciais do Ensino Fundamental I. v. 2. Campinas, SP: FE/Unicamp, 2010. p. 121-128.

GARNICA, Antonio Vicente Marafioti. História Oral e Educação Matemática - um inventário. Revista Pesquisa Qualitativa, São Paulo, v. 2, n. 1, p. 137-160, 2006.

GARNICA, Antonio Vicente Marafioti. Cartografias contemporâneas: mapa e mapeamento como metáforas para a pesquisa sobre a formação de professores de Matemática. Alexandria, v. 6, n. 1, p. 35-60, 2013.

GARNICA, Antonio Vicente Marafioti. Cartografias contemporâneas: mapear a formação de professores de Matemática. In: GARNICA, A. V. M. (Org.). Cartografias contemporâneas: mapeando a formação de professores de Matemática no Brasil. Curitiba: Appris, 2014. p. 39-66.

GARNICA, Antonio Vicente Marafioti; SOUZA, Luzia 
Aparecida de. Elementos de história da Educação Matemática. São Paulo: Cultura Acadêmica, 2012.

GRUPO DE PESQUISA HIFOPEM. As narrativas como metodologia e fonte de dados na pesquisa em Educação Matemática. In: OLIVEIRA, Andréia Maria Pereira de.; ORTIGÃO, Maria Isabel Ramalho. (Orgs.). Abordagens teóricas e metodológicas nas pesquisas em Educação Matemática. Brasília, DF: SBEM, 2018. v. 1, p. 90-112. (Coleção SBEM, 13).

GRUPO DE ESTUDO E PESQUISA SOBRE FORMAÇÃO DE PROFESSORES DE MATEMÁTICA - GEPFPM. Grupo de Estudo e Pesquisa sobre Formação de Professores de Matemática e as Revisões Sistemáticas. In: OLIVEIRA, Andréia Maria Pereira de.; ORTIGÃO, Maria Isabel Ramalho. (Org.). Abordagens teóricas e metodológicas nas pesquisas em Educação Matemática. Brasília, DF: SBEM, 2018. v. 1, p. 90-112. (Coleção SBEM, 13).

LOSANO, Ana Letícia; FIORENTINI, Dario. Análise das ênfases formativas de mestrados profissionais destinados a professores de matemática. Revista Internacional de Educação Superior, v. 4, p. 278-307, 2018.

LOSANO, Ana Leticia; FIORENTINI, Dario; VILLARREAL, Mónica Ester. The development of a mathematics teacher's professional identity during her first year teaching. Journal of Mathematics Teacher Education, v. 21, p. 287-315, 2017.

NACARATO, Adair Mendes; OLIVEIRA, Andréia Maria Pereira de; FERNANDES, Dea Nunes. Histórias da formação e de professores que ensinam Matemática: possiveis aproximações teórico-metodológicas. ZETETIKÉ, v. 25, p. 46-74, 2017.

NACARATO, Adair Mendes et al. Tendências das pesquisas brasileiras que têm o professor que ensina matemática como campo de estudo: uma síntese dos mapeamentos regionais. In: FIORENTINI, Dario; PASSOS, C. L. B.; LIMA, R. C. R. (Orgs.). Mapeamento da pesquisa acadêmica brasileira sobre o professor que ensina Matemática: período 2001-2012. Campinas, SP: FE/Unicamp. 2016. p. 319-337.

NACARATO, Adair Mendes; PASSOS, Cármen Lúcia Brancaglion; SILVA, Heloisa da. Narrativas na pesquisa em Educação Matemática: caleidoscópio teó- rico e metodológico. Boletim de Educação Matemática (Bolema), n. 49, p. 701-716, 2014.

NACARATO, Adair Mendes; PASSOS, Cármen Lúcia Brancaglion; GARNICA, Antonio Vicente Marafioti. Narrativas (auto)biográficas: artes de conhecer como professores de matemática se constituem profissionalmente (IV CIPA). 2010. (Mesa Redonda).

NÓVOA, António; FINGER, Matthias. (Orgs.). 0 método (auto)biográfico e a formação. Natal: EDUFRN; São Paulo: Paulus, 2010. [Coleção Pesquisa (auto) biográfica em Educação. Clássicos das Histórias de Vida)].

NÓVOA, António. Os professores e as histórias da sua vida. In: NÓVOA, A. (Org.). Vidas de professores. 2. ed. Porto: Porto Editora, 1995. p. 11-30 (Colecção Ciências da Educação).

OLIVEIRA, Andréia Maria Pereira de.; ORTIGÃO, Maria Isabel Ramalho. (Orgs.). Abordagens teóricas e metodológicas nas pesquisas em Educação Matemática. Brasília, DF: SBEM, 2018. v. 1, p. 90-112. (Coleção SBEM, 13).

PASSEGGI, Maria da Conceição; SOUZA, Elizeu Clementino de.; VICENTINI, Paula Perin. Entre a vida e a formação: pesquisa (auto)biográfica, docência e profissionalização. Educação em Revista, Belo Horizonte, v. 27, n. 1, p. 369-386, abr. 2011.

PASSEGGI, Maria da Conceição; SOUZA, Elizeu Clementino de. O movimento (auto)biográfico no Brasil: esboço de suas configurações no campo educacional. Investigación Cualitativa, v. 2, n. 1, p. 6-26, 2016.

PASSOS, Cármen Lúcia Brancaglion et al. Grupo de Estudos e Pesquisa em Educação Matemática - GEM: das narrativas de formação à pesquisa narrativa. In: OLIVEIRA, Andréia Maria Pereira de.; ORTIGÃO, Maria Isabel Ramalho. (Orgs.). Abordagens teóricas e metodológicas nas pesquisas em Educação Matemática. Brasília, DF: SBEM, 2018. v. 1, p. 210-233. (Coleção SBEM, 13).

ROLKOUSKI, Emerson. Vida de professores de matemática - (im)possibilidades de leitura. 2006. 288 f. Tese (Doutorado em Educação Matemática) - Instituto de Geociências e Ciências Exatas, 
Universidade Estadual Paulista, Rio Claro, 2006.

SILVA, Heloisa da. Centro de educação matemática

(CEM): fragmentos de identidade. 2006. 448 f. Tese (Doutorado em Educação Matemática) - Instituto de Geociências e Ciências Exatas, Universidade Estadual Paulista, Rio Claro, 2006.

SILVA, Marinéia dos Santos; SILVA, Heloisa da. Alguns Movimentos (de entrada e circulação) das narrativas na Educação Matemática. In: CONGRESSO INTERNACIONAL DE PESQUISA (AUTO)BIOGRÁFICA, 8., São Paulo. Anais... São Paulo: Universidade Cidade de São Paulo (UNICID). (no prelo).

SoUZA, Luzia Aparecida de. A formação de professores que ensinam matemática - história e perspectivas atuais. In: ENCONTRO NACIONAL DE PESQUISA EM HISTÓRIA DA EDUCAÇÃO MATEMÁTICA: formação de professores, história, cultura e política, 4., 2018, Campo Grande. Anais... Campo Grande: Universidade Federal do Mato Grosso do Sul (UFMS), 2018. Mesa Redonda.

SOUZA, Elizeu Clementino de. Pesquisa narrativa, (auto)biografias e história oral: ensino, pesquisa e formação em Educação Matemática. Ciências Humanas e Sociais em Revista, Rio de Janeiro, v. 32, n. 2, p. 13-27, jul./dez. 2010.

SOUZA, Elizeu Clementino de et al. Fios e teias de uma rede em expansão cooperação acadêmica no campo da pesquisa (auto)biográfica. Revista TEIAS, Rio de Janeiro, ano 11, n. 21, p. 01-17, jan./abr. 2010.

TIZZO, Vinícius Sanches. Mobilizações de narrativas na (e para a) formação de professores: potencialidades no (e a partir do) Programa Institucional de Bolsas de Iniciação à Docência. 2019. 488 f. Tese (Doutorado em Educação Matemática) - Instituto de Geociências e Ciências Exatas, Universidade Estadual Paulista, Rio Claro, 2019.

VIANNA, Carlos Roberto. Vidas e circunstâncias na Educação Matemática. 2000. 572 f. Tese (Doutorado em Educação) - Faculdade de Educação, Universidade de São Paulo, São Paulo, 2000.

ZAQUEU, Ana Cláudia Molina. O Programa Institucional de Bolsas de Iniciação à Docência (Pibid): perspectivas de ex-bolsistas. 2014. 269 f. Dissertação (Mestrado em Educação Matemática) - Instituto de Geociências e Ciências Exatas, Universidade Estadual Paulista, Rio Claro, 2014.

ZAQUEU-XAVIER, Ana Cláudia Molina. Narrativas na formação de professores: possibilidades junto ao Pibid da UFSCar. 2019. 297 f. Tese (Doutorado em Educação Matemática) - Instituto de Geociências e Ciências Exatas, Universidade Estadual Paulista, Rio Claro, 2019.

Recebido em: 31.01.2019

Aprovado em: 02.04.2019

Heloisa da Silva é Doutora em Educação Matemática pela UNESP - Campus de Rio Claro. Professora Assistente Doutora do Departamento de Educação Matemática do Instituto de Geociências e Ciências Exatas (IGCE)/UNESP - Campus de Rio Claro. GHOEM - Grupo História Oral e Educação Matemática. Apoio CNPq. e-mail: heloisas@rc.unesp.br

Universidade Estadual Paulista "Júlio de Mesquita Filho" - Campus de Rio Claro

Avenida 24A, 1515, Bela Vista, Rio Claro/SP, CEP 13.506-900. Tel: (19) 3526-9419

Marinéia Dos Santos Silva é Doutoranda do Programa de Pós-Graduação em Educação Matemática, IGCE/UNESP - Campus de Rio Claro. Mestre em Educação Matemática pela mesma instituição. Grupo História Oral e Educação Matemática (GHOEM). Apoio Capes. e-mail: marineia.ss@hotmail.com

Rua: Vinhedo, 277 - Residencial Bom Paraíso IV, apto. 21 - Parque Universitário.

CEP: 13.467-692, Americana/SP. Tel: (17) 99785-7001 